\title{
Cerebrospinal Fluid Corticotropin-Releasing Factor and Perceived Early-Life Stress in Depressed Patients and Healthy Control Subjects
}

\author{
Linda L Carpenter*,', Audrey R Tyrka', Christopher J McDougle², Robert T Malison ${ }^{3}$, Michael J Owens ${ }^{4}$, \\ Charles B Nemeroff ${ }^{4}$ and Lawrence H Price' \\ 'Mood Disorders Research Program and Laboratory for Clinical Neuroscience, Butler Hospital and Department of Psychiatry and Human \\ Behavior, Brown University School of Medicine, Providence, RI, USA; ²Department of Psychiatry, Indiana University School of Medicine, \\ Indianapolis, IN, USA; ${ }^{3}$ Department of Psychiatry, Yale University School of Medicine, and Connecticut Mental Health Center, New Haven, CT, \\ USA; ${ }^{4}$ Department of Psychiatry and Behavioral Sciences, Emory University School of Medicine, Atlanta, GA, USA
}

\begin{abstract}
Previous studies have reported elevated concentrations of cerebrospinal fluid (CSF) corticotropin-releasing factor (CRF) in patients with major depression. Elevations of CSF CRF have also been reported in adult laboratory animals exposed to the stress of brief maternal deprivation or maternal neglect in the neonatal or preweaning period. The present study was designed to determine whether major depression and a history of perceived early adversity in childhood are independently associated with elevated CSF CRF concentrations in adults. In this case-control study, 27 medication-free adults with major depression and 25 matched controls underwent standardized lumbar puncture for collection of a single CSF sample at I200. Subjects provided data about significant adverse early-life experiences and rated their global perceived level of stress during pre-school and preteen years on a six-point Likert scale. The mean difference in CSF CRF between depressed patients and controls did not reach statistical significance. In a regression model, perceived early-life stress was a significant predictor of CSF CRF, but depression was not. Perinatal adversity and perceived adversity in the preteen adversity years (ages 6-13 years) were both independently associated with decreasing CSF CRF concentrations. The relationship observed between perceived early-life stress and adult CSF CRF concentrations in this study closely parallels recent preclinical findings. More work is needed to elucidate the critical nature and timing of early events that may be associated with enduring neuroendocrine changes in humans. Neuropsychopharmacology (2004) 29, 777-784, advance online publication, 3I December 2003; doi: I 0.1038/sj.npp. I 300375
\end{abstract}

Keywords: corticotropin-releasing factor; cerebrospinal fluid; major depression; stress; hypothalamus-pituitary-adrenal axis

\section{INTRODUCTION}

Nearly five decades of research investigating basal and provoked hypothalamic-pituitary-adrenal (HPA) axis activity have established that disturbed regulation of this critical neuroendocrine system is associated with, and perhaps causally related to, depressive disorders. Suprapituitary-driven hypercortisolemia and impaired glucocorticoid negative feedback inhibition are now considered hallmarks of major depression (Holsboer, 1995). More recently, investigators have been able to examine directly the role of corticotropin-releasing factor (CRF), the principal neuropeptide-regulating stress responsivity, by

*Correspondence: LL Carpenter, Butler Hospital, 345 Blackstone Blvd., Providence, RI 02906, USA, Tel: + I-40I-455-6349, Fax: + I-40I455-6534, E-mail: Linda_Carpenter_MD@Brown.edu

Received 31 July 2003; revised 27 October 2003; accepted 20 November 2003

Online publication: I December 2003 at http://www.acnp.org/citations/ Npp I2010303343/default.pdf measuring CRF in cerebrospinal fluid (CSF) and indices of CRF neuronal activity in brain. As CRF serves as the main secretagogue for adrenocorticotropic hormone (ACTH), there has been substantial interest in measuring CSF concentrations of CRF in depressed patients. CRF also acts as an extrahypothalamic neurotransmitter outside of the HPA axis in the limbic system, cerebral cortex, and brainstem. Indeed, several lines of investigation suggest that the vast majority of CRF in CSF is derived from extrahypothalamic sources (Garrick et al, 1987; Geracioti et al, 1997; Hong et al, 1993; Kalin et al, 1987). It has been proposed that CRF neurons found in close neuroanatomical proximity to the ventricular system (eg in cortical, limbic, and brainstem regions) contribute the majority CRF to the CSF pool, and may be more relevant to depression and anxiety than those of hypothalamic origin (Post et al, 1982).

Most studies in which CRF levels have been measured in human lumbar CSF have shown increased levels of the peptide in depressed patients as compared with nondepressed controls (Banki et al, 1987, 1992a, b; France 
et al, 1988; Nemeroff et al, 1984; Widerlov et al, 1988), although discrepant reports have appeared (Geracioti et al, 1997, 1992; Kling et al, 1991; Pitts et al, 1995; Risch et al, 1992; Roy et al, 1987). However, secondary analyses in several of these negative studies pointed to higher CSF CRF concentrations in those patients who were dexamethasone suppression test nonsuppressors (Pitts et al, 1995; Roy et al, 1987) or in those with severe unipolar depression (Risch et al, 1992). Data showing normalization of CSF CRF values after successful antidepressant treatment with electroconvulsive therapy (Nemeroff et al, 1991; Rudorfer et al, 1991) or antidepressant medication (DeBellis et al, 1993), and the prediction of sustained long-term antidepressant response following normalization of CSF CRF (Banki et al, 1992a, b), support the notion that elevated CSF CRF concentrations reflect a state marker for depressive episodes. Fewer studies have addressed the possibility of persistent CRF dysfunction as a vulnerability trait for depression in humans. Support for the trait hypothesis is derived primarily from a growing preclinical literature, which demonstrates that adverse experiences during early life result in profound and irreversible effects on the mature organism's behavioral and neuroendocrine response to stress (Newport et al, 2002a, b).

Separation of rat pups from their mothers during the early postnatal period is one experimental paradigm used to study biological consequences of early stress. As adults, maternally deprived rats have increased anxiety, elevated synthesis, and mRNA expression of CRF in the hypothalamus and amygdala, and decreased responsiveness of the HPA axis to glucocorticoid negative feedback (Ladd et al, 1996; Meany et al, 1989; Plotsky and Meaney, 1993). An experimental model using unpredictable foraging conditions that leads to alterations in normal maternal-infant interaction has extended the finding of enduring CRF and HPA sequelae to non-human primates (Coplan et al, 1996, 2001). The rearing behavior exhibited by variable foraging demand (VFD) mothers is anxious, inconsistent, erratic, and sometimes frankly neglectful, presumably creating a psychological stressor for the infant via perception of 'insecure' attachment with mother (Rosenblum and Paully, 1984). As adults, the offspring of VFD mothers have CSF CRF concentrations that are chronically elevated in comparison with control groups (Coplan et al, 1996, 2001).

Recently, both the rodent maternal separation paradigm and the primate VFD model have produced evidence of 'timing effects,' (Mathew et al, 2002; Plotsky and Sanchez, 2003). In other words, neuroendocrine data from animals exposed to the experimental stressors at various distinct developmental stages have shown differential directions of abnormalities in HPA function, relative to controls. For example, infant rats exposed to a brief maternal separation stressor during postnatal days 2-14 show robust increases in stress-induced HPA hormones in adulthood. However, when the same paradigm is applied to rat pups during postnatal days 5-12, the opposite effect is seen, that is, a state of significant HPA hypoactive response is observed when the mature animals are stressed (Plotsky, 2003, unpublished data). Similarly, the application of the VFD stressor to mother-infant primate pairs at a later stage of development (starting at age 18-20 weeks $v s$ at age 10-12 weeks) essentially reverses the direction of the finding of significantly different mean CSF CRF in adulthood (Mathew et al, 2002). These and other studies, which include careful analysis of the developmental timing of exposure of young organisms to stress (van Oers et al, 1998), suggest that there are distinct and critical periods of brain development during which exposure to stress will impact the direction of enduring regulatory shift of the HPA axis.

The translation of hypotheses generated by such preclinical studies to human subjects is inherently challenging. Experimental designs frequently must rely on retrospective reporting of remote adverse events that are difficult to validate and quantify objectively. Breier et al, 1988 recruited subjects with a history of parental separation and found that a high proportion fulfilled the criteria for adult psychiatric disorders. Furthermore, the subgroup with a psychiatric history had higher basal cortisol concentrations than those with no such history or controls. Heim et al (2001, 2000, 2002) conducted clinical neuroendocrine investigations of the relationship between childhood trauma, adult depression, and HPA function. Plasma ACTH and cortisol responses of female subjects with depression, with and without early adverse life events, were examined in a standardized human psychosocial stress paradigm. Earlylife trauma was associated with enhanced ACTH responsivity, and the participants with both depression and a history of early-life trauma had elevated responses of both ACTH and cortisol (Heim et al, 2000). These subjects subsequently took part in a standardized CRF stimulation test (Heim et al, 2001). A self-reported history of childhood trauma, rather than a diagnosis of major depression, conferred the greatest degree of HPA axis dysregulation. Multiple regression analysis revealed that a history of childhood abuse per se was related to increased neuroendocrine stress hyperreactivity, and that the interaction between childhood abuse and adulthood trauma was the most powerful predictor of ACTH responsiveness (Heim et al, 2002).

Our study examined the relationship between selfreported early-life adversity, depression, and CSF CRF concentrations in a sample of adult depressed patients and nondepressed controls. Based on the preclinical and clinical literature, it was hypothesized that both the presence of major depressive illness and subjective reports of significant perceived early-life adversity would predict adult levels of CSF CRF.

\section{SUBJECTS AND METHODS}

In all, 27 adult outpatients fulfilling the DSM-IV criteria for unipolar major depressive disorder (MDD) and 25 healthy control subjects, selected to age and gender match the patient group, provided voluntary written informed consent to participate in this study. The protocol was approved by the institutional review boards of Yale University (New Haven, CT, USA) and Butler Hospital (Providence, RI, USA), and conducted at both institutions. Healthy subjects were recruited by postings around college/university campuses and on community bulletin boards. Depressed patients were recruited from those who presented seeking treatment in one of several clinical research trials for major depression. While several different versions of the Hamilton Depression Rating Scale (Hamilton, 1960) were used to 
determine eligibility for the clinical trials, all required the equivalent of a baseline score greater than 17. Semistructured diagnostic interviews were used to determine the presence of unipolar MDD (patient group) or the absence of any current and lifetime DSM-IV Axis I disorder (controls). Individuals with any other major Axis I comorbidity were excluded. While Axis II disorders were not formally assessed, those patients who presented with symptoms or characteristics suggestive of prominent personality pathology were excluded from entry into the CSF and depression treatment protocols. Also excluded were subjects with any clinically significant medical disorder, based on history, physical examination, and laboratory studies, which included a complete blood count, serum chemistries, liver and thyroid function tests, urine toxicology, electrocardiogram, and pregnancy test for women. All subjects were medication free for at least 2 weeks by the time of participation and were remunerated for participating. Depressed subjects underwent CSF sampling within 2 weeks prior to starting their clinical trial antidepressant treatment.

Subjects underwent a single standardized lumbar puncture (LP) and subsequently completed a qualitative questionnaire about early-life experiences. The questionnaire included items with face neutrality (eg gestational, neonatal, and childhood medical history; birth order; moving residence during childhood; family composition), as well as some items that more obviously assessed emotionally difficult childhood experiences (eg death of a close loved one; perceived parental availability; recalled physical, sexual, or emotional abuse; witnessing violence; parental substance abuse; family discord). Other items asked about perceived stress in childhood related to the subject's race, ethnic background, sexual orientation, or social status. Subjects were then asked to rate their perceived level of overall stress during pre-school years (ages birth-5 years) and preteen years (ages 6-13 years) on a six-point Likert scale, relative to what they considered normal for their peer cohort (global perceived early-life stress, GPELS). Subjects were aware that the study was intended to examine biological differences between depressed patients and healthy controls, but were not given further details about how demographic and historical information would be analyzed. Adverse early-life experiences were not discussed with subjects during the screening interviews or at any point during the LP.

All LP procedures were standardized to yield CSF samples at $1200 \pm 15 \mathrm{~min}$. All subjects agreed to comply with instructions for a modified diet and activity schedule in the $24 \mathrm{~h}$ preceding the LP. Specific measures were taken to reduce anxiety and HPA axis arousal associated with the LP procedure. Subjects did not disrobe or change into hospital gowns for the procedure, but wore loose clothes that were simply rolled away from the lumbar area. Subjects did not enter the procedure room until immediately before the LP began, and medical supplies such as needles and equipment used in the LP were kept out of subjects' view throughout the protocol. Low-volume soothing background music was played, and visually interesting posters decorated the wall before the subjects, who were placed in a comfortable leaning-forward seated position on a bed. Subjects were repeatedly encouraged to give feedback about their comfort so the physician could achieve a relatively pain-free LP through the use of comfortable positioning and liberal application of local anesthetic. Casual conversation between the subject and physician performing the LP continued throughout the procedure. If the procedure was not successful in producing a CSF sample by $30 \mathrm{~min}$ after the start of sterile preparations, the procedure was terminated.

Following the intradermal injection of $1 \%$ lidocaine, a 20 gauge introducer needle was used to penetrate skin and superficial tissue. The introducer is necessary because the Sprotte ${ }^{\circledR} 24$-gauge pencil point spinal needle is very thin and has a relatively dull tip. The spinal needle was then inserted, through the introducer, to the L4-L5 interspace. A total of $12 \mathrm{cc}$ of CSF was collected, immediately divided into $0.5 \mathrm{ml}$ aliquots, and frozen at $-80^{\circ} \mathrm{C}$ until assayed. Concentrations of CSF were measured by radioimmunoassay in duplicate using an antiserum (oC33) raised in rabbits against ovine CRF that was generously provided by Wylie Vale, Ph.D., of the Salk Institute (Banki et al, 1987).

In the initial statistical analyses, $t$-tests and $\chi^{2}$ tests were used to compare continuous measures (ie CSF CRF concentrations, age, GPELS values) and categorical variables (ie gender, dichotomous ratings on GPELS), respectively, between depressed patients and healthy controls. Pearson's correlation coefficients were calculated for relevant continuous variables. One subject did not complete the pre-school and preteen GPELS ratings and was excluded from analyses of these variables. Self-reported perinatal history was derived from the questionnaire items, and perinatal stress was scored as present if the subject reported having been the product of a medically complicated pregnancy or delivery (eg premature birth, nuchal cord, low birthweight), or if there was a prolonged hospital stay for neonatal care for any other reason. As the psychometric properties of the questionnaire have not been fully established, individual items describing other types of early-life stressors were not examined statistically with regard to CSF CRF concentrations.

Multiple regression analysis with forced entry was performed to determine the predictive value of four independent variables on adult CSF CRF concentrations: diagnosis (depressed $v s$ control), pre-school GPELS (1-6), preteen GPELS (1-6), and 'perinatal stress' rating (present $v s$ absent). All tests were two-tailed and considered significant at $p<0.05$.

Depression rating scale total scores were not available for enough patients to allow for the analysis of the relationships between severity of illness other key variables. In light of the potential bias introduced by depressed mood at the time of reporting early-life events, secondary analyses were conducted on the sample of healthy controls alone $(n=25)$. Pearson's correlation coefficients were determined for examination of the relationships between CSF CRF and the four key variables, and partial correlation coefficients were calculated for pre-school and preteen GPELS analyses. The small sample size precluded meaningful application of a regression analysis in this subgroup.

\section{RESULTS}

Depressed patients and healthy control subjects were similar with regard to age and sex (Table 1). Mean CSF 


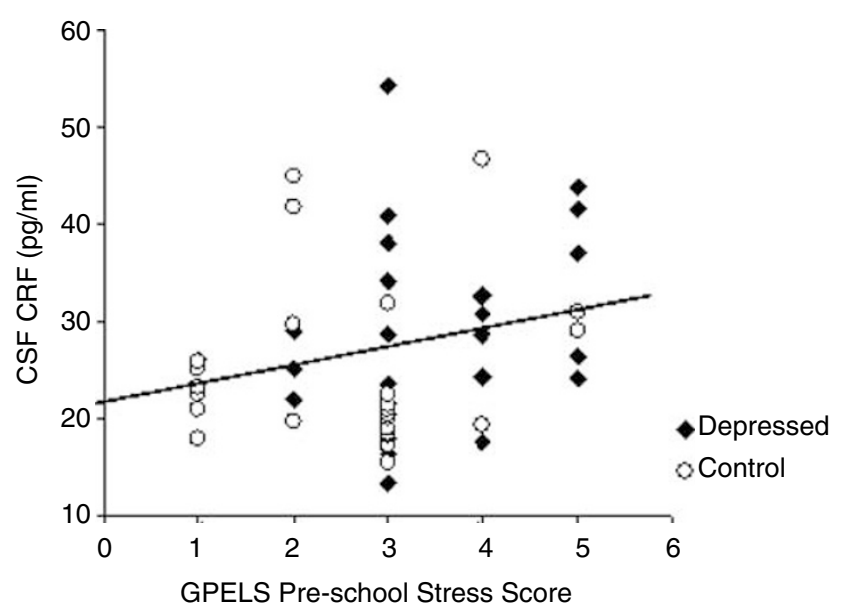

Figure I Relationship between CSF CRF and perceived pre-school stress rating.

CRF concentrations were higher among depressed patients, but the difference between groups did not reach statistical significance (mean $\pm \mathrm{SD}, \quad 29.0 \pm 9.4$ vs $24.9 \pm 8.6 \mathrm{pg} / \mathrm{ml}$; $t=1.6, \mathrm{df}=50, p=0.106)$. A similar proportion of each subject group endorsed the criteria for perinatal stress: $19 \%$ $(n=5)$ of depressives and $16 \%(n=4)$ of controls. Mean GPELS scores of perceived early-life stress during the preschool years were significantly higher for the group of depressed patients as compared with the controls $(3.4 \pm 1.1$ $v s 2.6 \pm 1.2 ; t=2.6, \mathrm{df}=49, p=0.012)$. Nearly half $(42 \%)$ of the depressed subjects rated themselves as having had a 'higher than average' degree of exposure to stress during their childhood from birth through age 5 years, yet only four $(16 \%)$ of the controls perceived a high level of stress relative to their peers during that period $\left(\chi^{2}=4.2\right.$, $p=0.04)$. The two groups did not differ statistically with regard to GPELS ratings of stress during the preteen years $(4.1 \pm 1.2$ vs $3.5 \pm 1.3 ; t=1.639, \mathrm{df}=49, p=0.108)$; nine (53\%) of depressed subjects and nine (48\%) of controls rated themselves as having experienced above average levels of stress during ages 6-13 years. Scores on the pre-school and preteen GPELS correlated significantly with each other $(r=0.62, p<0.001)$, reflecting the fact that many subjects endorsed a consistent degree of perceived adversity across their childhood and latency years.

CSF CRF values for the pooled (depressed and control) subjects ranged from 13.4 to $54.1 \mathrm{pg} / \mathrm{ml}$, with a median value of $24.1 \mathrm{pg} / \mathrm{ml}$ and mean $\pm \mathrm{SD}$ of $27.06 \pm 9.18 \mathrm{pg} / \mathrm{ml}$ (Figure 1). Relationships between perceived early-life stress ratings and CSF CRF concentrations for the pooled groups were analyzed in a regression model that contained the four predictor variables and accounted for $22 \%$ of the variance in CSF CRF concentration $(\mathrm{F}=3.3 ; \mathrm{df}=4, p=0.018)$ (Table 2). Pre-school GPELS score was a significant positive predictor ( $\beta=0.438, p=0.015)$ of CSF CRF concentration in this model. Preteen GPELS score emerged as a significant negative predictor of CSF CRF concentration $(\beta=-0.385$, $p=0.029)$, as did perinatal stress $(\beta=-0.317, p=0.023)$. The presence of adult major depression was not a significant predictor of CSF CRF concentrations $(\beta=0.165, p=0.241)$.
Table I Comparison of Subjects Based on the Presence of Major Depression

\begin{tabular}{|c|c|c|c|}
\hline & $\begin{array}{c}\text { Depressed } \\
(n=27)\end{array}$ & $\begin{array}{l}\text { Controls } \\
(n=25)\end{array}$ & $p$-value \\
\hline Age (mean $\pm S D)$ (years) & $37.4 \pm 13.0$ & $34.0 \pm 11.5$ & NS \\
\hline Gender (\% (n)) & - & - & NS \\
\hline Male & $41 \%(11)$ & $48 \%(12)$ & \\
\hline Female & $59 \%(16)$ & $52 \%(13)$ & \\
\hline CSF CRF (mean pg/ml $\pm \mathrm{SD}$ ) & $29.0 \pm 9.4$ & $24.9 \pm 8.5$ & 0.106 \\
\hline \multicolumn{4}{|l|}{ Perinatal stress } \\
\hline (Any pregnancy/obstetrical/ & $5(19 \%)$ & $4(16 \%)$ & NS \\
\hline
\end{tabular}

\begin{tabular}{|c|c|c|c|}
\hline \multicolumn{4}{|l|}{ GPELS (global perceived early-life stress) } \\
\hline \multicolumn{4}{|c|}{ Pre-school years (ages birth-5 years) rating } \\
\hline Score $(\text { mean } \pm S D)^{\mathrm{a}}$ & $3.4 \pm 1.1$ & $2.6 \pm 1.2$ & 0.012 \\
\hline 'High' categorical rating $(n(\%))^{b}$ & II (42\%) & $4(16 \%)$ & 0.039 \\
\hline \multicolumn{4}{|l|}{ Preteen years (ages 6-13 years) rating } \\
\hline Score $(\text { mean } \pm S D)^{a}$ & $4.1 \pm 1.2$ & $3.5 \pm 1.3$ & 0.108 \\
\hline 'High' categorical rating $(n(\%))^{b}$ & $9(53 \%)$ & $8(47 \%)$ & NS \\
\hline \multicolumn{4}{|c|}{$\begin{array}{l}\text { 'Six-point Likert scale where I = least stress to } 6=\text { most stress. } \\
\text { 'Dichotomization of GPELS ratings: 'high' stress defined as 'more stressful than } \\
\text { most kids', 'extremely stressful', or 'the most stress I have ever known;' 'low' } \\
\text { stress defined as 'essentially stress free', 'less stress than most kids', or 'about } \\
\text { average'. } \\
\text { NS = nonsignificant. }\end{array}$} \\
\hline
\end{tabular}

Table 2 Multiple Linear Regression Analysis: Predictors of CSF CRF in Adults

\begin{tabular}{llrr}
\hline Predictor & $\begin{array}{l}\text { Relationship } \\
\text { to CRF }\end{array}$ & $\boldsymbol{\beta}^{\mathrm{b}}$ & p-value \\
\hline Pre-school stress (GPELS ages 0-5 years) & Positive & 0.438 & 0.015 \\
$\begin{array}{l}\text { Perinatal stress (present vs absent) } \\
\text { (pregnancy/obstetrical/ }\end{array}$ & Negative & -0.317 & 0.023 \\
neonatal complications) & & & \\
Preteen stress (GPELS ages 6-13 years) & & & \\
Current major depression & Negative & -0.385 & 0.029 \\
& Positive & 0.165 & 0.241 \\
\hline
\end{tabular}

${ }^{\text {aS }}$ ix-point Likert scale where $1=$ least stress to $6=$ most stress.

${ }^{\mathrm{b}}$ Standardized regression coefficient.

Data from the 25 healthy control subjects were examined independently to remove possible biases from self-reporting perceived early-life adversity while in a depressed state. Among healthy controls, perceived levels of stress during the pre-school years (birth-age 5 years) were associated with elevated CSF CRF concentrations at a trend level ( $r=0.34, p=0.09)$ and perceived levels of stress during the latency developmental period (ages 6-13 years) were significantly associated with CSF CRF concentrations in the opposite direction $(r=-0.42, p=0.04)$. Healthy 
subjects' age and reports of perinatal adversity showed no relationship with CSF CRF concentrations.

\section{DISCUSSION}

Consistent with the mixed findings with respect to CSF CRF in major depression described in the literature, we found that CSF CRF concentrations were somewhat higher in a group of medication-free depressed adults than in nondepressed healthy controls, but this difference fell short of statistical significance. The notion that depression is independently associated with CRF hyperactivity was also not supported by the results of our regression analysis, where the presence of depression failed to predict CSF CRF concentrations. Rather, the data suggest that perceived early-life adversity, commonly reported among depressed patients, may be a mediating variable between depression and adult CSF CRF concentrations, and that the timing of exposure to adversity may impact the direction of HPA regulation shift. Assessments of (perceived or observed) early-life stress have not been included in previously published reports describing elevated CSF CRF concentrations among depressed samples.

We found perceived levels of adversity in different stages of development to be associated with adult CSF CRF concentrations, independent of major depression. In the pooled subjects group, global self-ratings of stress during pre-school years emerged as a significant positive predictor of adult CSF CRF concentration. This finding is consistent with the growing body of preclinical research, suggesting that exposure to stress during critical early developmental periods induces enduring upregulation in HPA function, often indicated by elevated CSF CRF concentrations, which may represent a biological vulnerability for depression, anxiety, or other pathology in adulthood. We are aware of one other clinical research group that recently presented preliminary data showing a similar positive relationship between self-reported childhood trauma scores and CSF CRF concentrations in adult males with personality disorders (Lee et al, 2002).

Perhaps, more intriguing is our finding that perceived early-life stress was associated with a relatively increased or decreased CSF CRF concentrations depending on the reported developmental timing of the perceived stress exposure (Table 2). Whereas stress before age 6 years was associated with elevated CSF CRF concentrations, both perinatal stress and preteen stress were predictive of lower CRF concentrations. A pattern of hypoactive HPA responsivity associated with perinatal stress was also suggested by results of a study of 8-14 year olds in whom a history of premature birth was associated with attenuated salivary cortisol and heart rate responses to a standardized psychosocial stressor in comparison to full-term subjects (Buske-Kirschbaum et al, 2000). Similarly, in preclinical work, prenatal immune challenge has been found to diminish HPA axis reactivity in adult rats (Reul et al, 1994). Other preclinical investigations have revealed developmental effects similar to those found in the present study. A recent study of non-human primates reared in the VFD stress paradigm shifted the age of exposure to VFD rearing from that of the previous studies. When VFD rearing began with infants at 18 weeks of age, the results were significantly lower CSF CRF concentrations compared to control primates, whereas prior studies of VFD exposure beginning at 10-12 weeks revealed increases in CSF CRF compared to controls (Mathew et al, 2002). There is also some evidence of critical periods for HPA axis sensitivity to environmental stimuli in rodents, with heightened sensitivity in the first week of life and again after weaning (Meany et al, 1996; Plotsky et al, unpublished observations).

The present findings may also be consistent with a hypothesis recently advanced by Yehuda et al (2001) that early childhood stressors may be more likely to predispose to the types of HPA axis changes typically seen with depression, whereas stressors occurring later in life may lead to neuroendocrine supersuppression and PTSD. Support for the hypothesis that earlier stressors are associated with a neuroendocrine pattern characteristic of depression is provided by a study by Petitto et al (1992), who found that among mood disorder patients with a history of parental or sibling loss before the age of 20 years, age at first loss was strongly and negatively correlated with postdexamethasone cortisol levels. These different lines of investigation support the notion that the timing of stress exposure may be a critical determinant of enduring neuroendocrine stress responsivity. Additional research into the neuroendocrine and behavioral effects of stressors with regard to the quality, intensity, and timing of early-life adversity is needed for a more complete understanding of the complex relationship between stress, HPA axis function, and psychopathology.

Our findings are limited in some ways, which deserve consideration. A retrospective, self-report method was used to capture the nature and perceived intensity of early-life stressors. Occurrence of the stressors identified by our qualitative questionnaire and the GPELS scores were not independently confirmed. These measures reflected perceived and recalled experiences, which may not be as strongly associated with enduring HPA disturbances as stressors that are experimentally standardized or 'objectively' quantified.

Retrospective assessment of early-life stress is controversial and currently a topic of much consideration among researchers. Without benefit of a subject cohort prospectively and continuously followed from birth (and perhaps prenatally) with close attention to even subtle environmental influences throughout development, it is impossible to conclude that one has access to valid and complete information about early-life adversity. Even when interview assessments of stress are conducted in 'prospectively' followed cohorts at points in close temporal proximity to exposure to objectively defined adverse conditions, the subject's report necessarily reflects his or her gestalt of discrete events, context, and unique interpretations. Unless biological data (eg vitals signs evidence of autonomic nervous system arousal, acute cortisol release) are available at the time of exposure to a stressor, investigators must rely on subjects' perceptions and reports of how much stress they experienced.

Clinical investigations into the relationship between adverse developmental environments and adult health outcomes are often considered limited by the use of self- 
report data. While prospectively observed and objectively validated life events might generally be considered the most scientifically valid, perceived reality may be the more relevant determinant of health outcomes when it comes to stress biology. As many limbic and higher cortical brain structures provide input to the hypothalamus during the interpretation of a stimulus as threatening, there will be considerable individual variability in the degree of HPA axis arousal produced by any given stimulus. At least among healthy individuals, one's subjective, uniquely integrated perception of severity of stress probably 'counts' more than how stressful the experience is objectively rated by external standards. Perhaps more problematic is the fact that such perceptions may be distorted when recall of childhood adversity is conducted in adult individuals in an acutely depressed state. Indeed, when compared with our healthy subjects, depressed individuals were significantly more likely to rate their early lives as highly stressful. We cannot conclude whether such a finding simply represents recall biases due to prominent depressive cognitions, or whether it reflects the fact that individuals exposed to stress are at a greater risk of developing depression in adulthood. However, the replication of some of the significant relationships we found between CSF CRF concentrations and perceived early-life stress in a sizable group of healthy controls makes it less likely that our results are attributable to that potential confound. Serial assessment of perceived early-life stress in a depressed cohort during various clinical states (eg depressed, partially remitted, fully remitted, relapsed) would help elucidate if and how depression impacts the reporting of early-life adversity.

The GPELS, a simple Likert self-rating of global perceived stress in two distinct time periods, is not a validated measure. We developed the GPELS to address the fact that available, psychometrically established instruments of early-life trauma were insufficiently sensitive to many types of events which subjects have anecdotally described as highly stressful. No published scale incorporates the breadth of items (eg perinatal health, perceived stress due to race, sexual identity, or ethnic group) that we thought might be relevant in an investigation of CSF CRF concentrations. For example, recent research in rodents has shown that exposure to bacterial endotoxin during the neonatal period permanently alters the development of the HPA axis, resulting in hypersecretion of corticosterone after subsequent stress exposure even in adulthood (Hodgson et al, 2001; Shanks et al, 2000). This underscores the need to assess a broad range of early-life stressors, including physically as well as psychologically distressing experiences. Any perceived or actual threat to an organism's integrity and survival has the potential to stimulate CRF release and initiate a multisystem stress response in the service of selfprotection and self-preservation. While sexual and physical abuse have consistently been identified as early-life stressors related to adult psychopathology (Browne and Finkelhor, 1986), the psychiatric and neuroendocrine consequences of other types of stressors have not been systematically studied in humans. Given the practical and ethical limitations of exposing human neonates and young children to experimentally manipulated adverse experiences, future studies in this area will likely continue to be characterized by a lack of standardization of stressors and limited ability to control potentially confounding variables. Whether recalled severity of global adversity reflects a valid and reliable summary of overall stress burden during a period of time remains to be explored in future studies. However, its possible utility is supported by results of a recent study showing that retrospective, self-ratings of global childhood victimization, rather than objective, externally validated data with respect to specific incidents of childhood abuse, were associated with the development of unexplained pain syndromes in adulthood (Raphael et al, 2001). Another example providing validation for the use of self-report assessment of global perceived stress for predicting important health outcomes comes from 35-year follow-up data on healthy undergraduate students who participated in the Harvard Stress Mastery Study (Russek and Schwartz, 1997a, b; Russek et al, 1998). Those describing themselves as exposed to low levels of parental caring were found to have a four-fold greater risk of suffering from chronic illnesses such as coronary artery disease, hypertension, duodenal ulcer, alcoholism, and depression in midlife. To ensure that the extraneous state and trait variables are not shaping the reporting styles of participants, future studies that involve global self-ratings or measures of perceived stress might also include assessments of adult 'temperament' or neuroticism measures, as well as indices of state and trait anxiety.

Research investigating the neurobiological consequences of early-life adversity in human samples poses considerable methodological challenges, and also holds great promise for the detection of biological risk factors and the prevention of psychiatric illness. Findings from such studies, in conjunction with the recent emergence of drugs that target glucocorticoids and CRF receptors in the adult brain, could lead to effective prophylaxis or treatment of psychiatric symptoms in individuals who have been exposed to earlylife adversity.

\section{ACKNOWLEDGEMENTS}

This work was supported by a 1998 Young Investigator Award from NARSAD (LLC), and NIH grants MH-42088 (CBN), and MH-58922 (CBN). We gratefully acknowledge Jason Siniscalchi, MS and Kathleen Reilly, MS for assistance with data analysis, Julia C Burke, MSN, CS for excellent clinical care to research subjects, and Christine A Richard for administrative support. This work was presented in part at the annual meetings of the American College of Psychopharmacology (poster, 2001, Hawaii), the American Psychopathological Association (poster, 2002, NewYork City), the Society for Biological Psychiatry (poster, 2002, Philadephia), and the American Psychiatric Association (poster and industry-sponsored symposium, 2002, Philadelphia).

Author disclosures: Linda L Carpenter, MD discloses the following: payment for consultant services to Organon, Cephalon, GlaxosmithKline; grant/research support from Cyberonics, Pfizer, Merck, Corcept Therapeutics, Cephalon, Medtronics; speakers bureau honoraria from Cyberonics, Abbott, Pfizer, Somerset, Organon, Wyeth. Audrey R Tyrka $M D, P h D$ reports no disclosures. Christopher McDougle, $M D$ discloses research grants, consulting payments, and speakers 
bureau honoraria from Pfizer, Inc.; research grants, consulting payments, and speakers bureau honoraria from Janssen Pharmaceutica; research grants and consulting payments from Eli Lilly and Co.; speakers bureau honoraria from Bristol-Myers Squibb Co.; research grants from AstraZeneca; research grants and consulting payments from Repligen Corp. Robert T Malison, MD discloses a consulting payment from Pfizer, Inc. Michael J Owens, PhD discloses being a research grant recipient from GlaxoSmithKline, Pfizer Inc., Merck, UCB Pharma, NARSAD and NIH. He reports no standing consultancies or speakers bureau membership. Charles $B$ Nemeroff $M D, P h D$ discloses grants/research support from: Abbott Laboratories; AFSP; AstraZeneca; Bristol-Myers-Squibb; Eli Lilly; Forest Laboratories; GlaxoSmithKline; Janssen Pharmaceutica; Merck; NARSAD; NIMH; Pfizer Pharmaceuticals; Stanley Foundation/NAMI; Wyeth-Ayerst. Dr Nemeroff discloses receiving payments for consulting services to: Abbott Laboratories; Acadia Pharmaceuticals; AstraZeneca; Bristol-Myers-Squibb; Corcept; Cypress Biosciences; Cyberonics; Eli Lilly; Forest Laboratories; GlaxoSmithKline; Janssen Pharmaceutica; Merck; Neurocrine Biosciences; Novartis; NPS Pharmaceuticals Organon; Otsuka; Sanofi; Scirex; Somerset; Wyeth-Ayerst. Dr Nemeroff discloses receiving speakers bureau honoraria from: Abbott Laboratories; AstraZeneca; Bristol-Myers-Squibb; Eli Lilly; Forest Laboratories; GlaxoSmithKline; Janssen Pharmaceutica; Organon; Otsuka; Pfizer Pharmaceuticals; WyethAyerst. Dr Nemeroff is a stockholder with Corcept and Neurocrine Biosciences. Dr Nemeroff serves on the Board of Directors for the following: American Foundation for Suicide Prevention (AFSP); Cypress Biosciences; George West Mental Health Foundation; Novadel Pharma; Heinz C Prechter Fund for Manic Depression. Dr Nemeroff holds the following patents: (US 6,375,990 B1) for method and devices for transdermal delivery of lithium; method to estimate serotonin and norepinephrine transporter occupancy after drug treatment using patient or animal serum (provisional filing April, 2001). Lawrence $H$ Price, MD discloses payment for consulting services to Pfizer, GlaxoSmithKline, Bristol-Myers Squibb; speakers bureau honoraria from GlaxoSmithKline, AstraZeneca; research support from Merck, Thuris, Medtronic, Cyberonics, and Cephalon.

\section{REFERENCES}

Banki CM, Bissette G, Arato M, O'Connor L, Nemeroff CB (1987). Cerebrospinal fluid corticotropin-releasing factor-like immunoreactivity in depression and schizophrenia. Am J Psychiatry 144: 873.

Banki CM, Karmacsi L, Bissette G, Nemeroff CB (1992a). Cerebrospinal fluid neuropeptides in mood disorder and demetia. J Affect Disorders 25: 39-46.

Banki CM, Karmacsi L, Bissette G, Nemeroff CB (1992b). CSF corticotropin-releasing hormone and somatostatin in major depression: response to antidepressant treatment and relapse. Eur Neuropsychopharmacol 2: 107-113.

Breier A, Kelsoe Jr JR, Kirwin PD, Beller SA, Wolkowitz OM, Pickar D (1988). Early parental loss and development of adult psychopathology. Arch Gen Psychiatry 45: 987-993.

Browne A, Finkelhor D (1986). Impact of child sexual abuse: a review of the research. Psychol Bull 99: 66-77.
Buske-Kirschbaum A, Jobst S, Wilkes C, Hellhammer DH (2000). American Psychosomatic Society, Vol. Abstract number 1392. Savannah, GA.

Coplan J, Andrews M, Rosenblum L, Owens M, Friedman S, Gorman J et al (1996). Persistent elevations of cerebrospinal fluid concentrations of corticotropin-releasing factor in adult nonhuman primates exposed to early-life stressors: Implications for the pathophysiology of mood and anxiety disorders. Proc Natl Acad Sci USA 93: 1619-1623.

Coplan JD, Smith EL, Altemus M, Scharf BA, Owens MJ, Nemeroff CB et al (2001). Variable foraging demand rearing: sustained elevations in cisternal cerebrospinal fluid corticotropin-releasing factor concentrations in adult primates. Biol Psychiatry 50: 200-204.

DeBellis MD, Gold PW, Geracioti TM, Listwak SJ, Kling MA (1993). Association of fluoxetine treatment with reductions in CSF concentrations of corticotropin-releasing hormone and arginine vasopressin in patients with major depression. Am J Psychiatry 150: $656-657$.

France RD, Urban B, Krishnan KRR, Bissette G, Banki CM, Nemeroff C et al (1988). CSF corticotropin-releasing factor-like immunoactivity in chronic pain patients with and without major depression. Biol Psychiatry 23: 86-88.

Garrick NA, Hill JL, Szele FG, Tomai TP, Gold PW, Murphy DL (1987). Corticotropin-releasing factor: a marked circadian rhythm in primate cerebrospinal fluid peaks in the evening and is inversely related to the cortisol circadian rhythm. Endocrinology 121: 1329-1334.

Geracioti Jr TD, Loosen PT, Orth DN (1997). Low cerebrospinal fluid corticotropin-releasing hormone concentrations in eucortisolemic depression. Biol Psychiatry 42: 165-174.

Geracioti TD, Orth DN, Ekhator NN, Blumenkopf B, Loosen PT (1992). Serial cerebrospinal fluid corticotrophin-releasing hormone concentrations in healthy and depressed humans. J Clin Endocrinol Metab 74: 1325-1330.

Hamilton M (1960). A rating scale for depression. J Neurol Neurosurg Psychiatry 23: 56-62.

Heim C, Newport DJ, Bonsall R, Miller AH, Nemeroff CB (2001). Altered pituitary-adrenal axis responses to provocative challenge tests in adult survivors of childhood abuse. $A m J$ Psychiatry 158: 575-581.

Heim C, Newport DJ, Heit S, Graham YP, Wilcox M, Bonsall R et al (2000). Pituitary-adrenal and autonomic responses to stress in women after sexual and physical abuse in childhood. JAMA 284: 592-597.

Heim C, Newport DJ, Wagner D, Wilcox M, Miller AH, Nemeroff CB (2002). The role of early adverse experience and adulthood stress in the prediction of neuroendocrine stress reactivity in women: a multiple regression analysis. Depression Anxiety 15: 117-125.

Hodgson DM, Knott B, Walker FR (2001). Neonatal endotoxin exposure influences HPA responsivity and impairs tumor immunity in Fischer 344 rats in adulthood. Pediatr Res 50: $750-755$.

Holsboer F (1995). In: Bloom F, Kupfer D (eds). Psychopharmacology: The Fourth Generation of Progress. Raven Press, Ltd: New York. pp 957-999.

Hong SK, Gold PW, Herkenham M (1993). Hypothalamic paraventricular lesions decrease corticotropin-releasing hormone in the CSF and elevate TRH mRNA in the locus coeruleus (Abstract 31211). Soc Neurosci Abstr 19: 762.

Kalin NH, Shelton SE, Barksdale CM, Brownfield MS (1987). A diurnal rhythm in cerebrospinal fluid corticotropin-releasing hormone different from the rhythm of pituitary-adrenal activity. Brain Res 426: 385-391.

Kling MA, Roy A, Doran AR, Calabrese JR, Rubinow DR, Whitfield Jr HJ et al (1991). Cerebrospinal fluid immunoreactive corticotropin-releasing hormone and adrenocorticotropin secre- 
tion in Cushing's disease and major depression: potential clinical implications. J Clin Endocrinol Metab 72: 260-271.

Ladd CO, Owens MJ, Nemeroff CB (1996). Persistent changes in corticotropin-releasing factor neuronal systems induced by maternal deprivation. Endocrinology 137: 1212-1218.

Lee R, Kasckow J, Coccaro E (2002). American Psychiatric Association 155th Annual Meeting. Philadelphia, PA.

Mathew SJ, Coplan JD, Smith EL, Scharf BA, Owens MJ, Nemeroff $\mathrm{CB}$ et al (2002). Cerebrospinal fluid concentrations of biogenic amines and corticotropin-releasing factor in adolescent nonhuman primates as a function of the timing of adverse early rearing. Stress 5: 185-193.

Meany MJ, Aitken DH, Viau V, Sharma S, Sarrieau A (1989). Neonatal handling alters adrenocortical negative feedback sensitivity and hippocampal type II glugogorticoid receptor binding in the rat. Neuroendocrinology 50: 597-604.

Meany MJ, Diorio J, Francis D, Widdowson J, LaPlante P, Caldji C et al (1996). Early environmental regulation of forebrain glucocorticoid receptor gene expression: Implications for adrenocortical responses to stress. Dev Neurosci 18: 49-72.

Nemeroff C, Widerlov E, Bissette G, Walleus H, Karlsson I, Eklund $\mathrm{K}$ et al (1984). Elevated concentrations of CSF corticotropinreleasing factor-like immunoreactivity in depressed patients. Science 226: 1342-1344.

Nemeroff CB, Bissette G, Akil H, Fink M (1991). Neuropeptide concentrations in the CSF of depressed patients treated with electroconvulsive therapy. Corticotrophin-releasing factor, $\beta$ endorphin and somatostatin. Br J Psychiatry 158: 59-63.

Newport DJ, Stowe ZN, Nemeroff CB (2002a). Parental depression: animal models of an adverse life event. Am J Psychiatry 159: $1265-1283$.

Newport DJ, Wilcox MM, Stowe ZN (2002b). Maternal depression: a child's first adverse life event. Semin Clin Neuropsychiatry 7: 113-119.

Petitto JM, Quade D, Evans DL (1992). Relationship of object loss during development to hypothalamic-pituitary-adrenal axis function during major affective illness later in life. Psychiatry Res 44: 227-236.

Pitts AF, Samuelson SD, Meller WH, Bissette G, Nemeroff CB, Kathol RG (1995). Cerebrospinal fluid corticotripin-releasing hormone, vasopressin, and oxytocin concentrations in treated patients with major depression and controls. Biol Psychiatry 38: 330-335.

Plotsky PM, Meaney MJ (1993). Early postnatal experience alters hypothalamic corticotropin-releasing factor (CRF) mRNA, median eminence CRF content and stress-induced release in adult rats. Mol Brain Res 18: 195-200.

Plotsky PM, Sanchez MM (2003). AAAS Annual Meeting. Denver, CO.
Post RM, Gold P, Rubinow DR, Ballenger JC, Bunney Jr WE, Goodwin FK (1982). Peptides in the cerebrospinal fluid of neuropsychiatric patients: an approach to central nervous system peptide function. Life Sci 31: 1-15.

Raphael KG, Widom CS, Lange G (2001). Childhood victimization and pain in adulthood: a prospective investigation. Pain 92: 283-293.

Reul JM, Stec I, Wiegers GJ, Labeur MS, Linthorst AC, Arzt E et al (1994). Prenatal immune challenge alters the hypothalamicpituitary-adrenocortical axis in adult rats. J Clin Invest 93: 26002607.

Risch SC, Lewine RJ, Kalin NH, Jewart RD, Risby ED, Caudle JM et al (1992). Limbic-hypothalamic-pituitary-adrenal axis activity and ventricular-to-brain ratio studies in affective illness and schizophrenia. Neuropsychopharmacology 6: 95-100.

Rosenblum LA, Paully GS (1984). The effects of varying environmental demands on maternal and infant behavior. Child Dev 55: 305-314.

Roy A, Pickar D, Paul S, Doran A, Chrousos GP, Gold PW (1987). CSF corticotropin-releasing hormone in depressed patients and normal control subjects. Am J Psychiatry 144: 641-645.

Rudorfer MV, Risby ED, Osman OT, Gold PW, Potter WZ (1991). Hypothalamic-pituitary-adrenal axis and monoamine transmitter activity in depression: a pilot study of central and peripheral effects of electroconvulsive therapy. Biol Psychiatry 29: 253-264.

Russek LG, Schwartz GE (1997a). Feelings of parental caring predict health status in midlife: a 35-year follow-up of the Harvard Mastery of Stress Study. J Behav Med 20: 1-13.

Russek LG, Schwartz GE (1997b). Perceptions of parental caring predict health status in midlife: a 35-year follow-up of the Harvard Mastery of Stress Study. Psychosom Med 59: 144-149.

Russek LG, Schwartz GE, Bell IR, Baldwin CM (1998). Positive perceptions of parental caring are associated with reduced psychiatric and somatic symptoms. Psychosom Med 60: 654-657.

Shanks N, Windle RJ, Perks PA, Harbuz MS, Jessop DS, Ingram CD et al (2000). Early-life exposure to endotoxin alters hypothalamic-pituitary-adrenal function and predisposition to inflammation. Proc Natl Acad Sci USA 97: 5645-5650.

van Oers HJ, de Kloet ER, Levine S (1998). Early $v s$ late maternal deprivation differentially alters the endocrine and hypothalamic responses to stress. Brain Res Dev Brain Res 111: 245-252.

Widerlov E, Bissette G, Nemeroff CB (1988). Monoamine metabolites, corticotropin releasing factor and somatostatin as CSF markers in depressed patients. J Affect Disord 14: 99-107.

Yehuda R, Golier J, Wong C, Grossman R (2001). American College of Neuropsychopharmacology 40th Annual Meeting. Waikoloa, HI. 